\title{
Portfolio Choice and Liquidity Constraints*
}

\author{
Michael Haliassos ${ }^{\dagger}$ and Alexander Michaelides ${ }^{\ddagger}$ \\ University of Cyprus
}

First draft: June 15, 1999

October 26, 1999

\footnotetext{
${ }^{*}$ We are grateful to Joe Altonji, James Banks, Christopher Carroll, Angus Deaton, Deborah Lucas, Sydney Ludvigson, Steve Pischke, Nick Souleles, Steve Zeldes, Jose Victor Rios-Rull, and conference participants at the 1999 NBER Summer Institute Workshop on the Aggregate Implications of Microeconomic Consumption Behavior for very helpful comments and suggestions. We would also like to thank participants at the 1999 AS.S.E.T. meetings at Tel Aviv University, and at the TMR meetings on Savings and Pensions in Venice, as well as seminar participants at INSEAD and the University of Cyprus for many helpful comments. Any errors or omissions are the responsibility of the authors.

${ }^{\dagger}$ Address: Department of Economics, University of Cyprus, PO BOX 20537, 1678, Nicosia, Cyprus. Email: Haliassos@aya.yale.edu.

${ }^{\ddagger}$ Address: Department of Economics, University of Cyprus, PO BOX 20537, 1678, Nicosia, Cyprus. Email: alexm@ucy.ac.cy.
} 


\begin{abstract}
This paper generalizes Deaton's (1991) approach to saving under borrowing constraints to incorporate portfolio choice. For infinite horizon, impatient consumers, effects of risk aversion, prudence and temperance on portfolios can be different from those obtained in atemporal models. We confirm the surprising result of portfolio specialization in stocks (Heaton and Lucas, 1997) using a different earnings process, and we provide a rationale for why risk aversion and habit persistence cannot reverse it. We then show that positive correlation of stock returns with permanent, but not transitory, earnings shocks can generate demand for bonds and zero stockholding. However, existing empirical estimates of such correlations are at variance with portfolio data. We offer an alternative explanation of observed stock holding patterns based on fixed stock market entry costs. The entry cost required to keep impatient households out of the stock market is surprisingly small. This suggests that entry costs could generate the observed reluctance of households to undertake stockholding and explain the slowness in the emergence of an "equity culture" among households.
\end{abstract}

JEL Classification: E2, G11.

Key Words: Precautionary Saving, Portfolio Choice, Liquidity Constraints, Buffer Stock Saving, Entry Costs. 


\section{Introduction}

Moral hazard and adverse selection problems have prevented the emergence of markets that insure households against idiosyncratic earnings risk. Such market incompleteness has stimulated substantial research interest in models of precautionary saving. ${ }^{1}$ Following Deaton (1991) and Carroll $(1992,1997)$, another subset of this literature has focused on the interaction between the precautionary saving motive and liquidity constraints (the buffer stock saving model). The evidence adduced by Gourinchas and Parker (1999) and Ludvigson and Michaelides (1999) can be considered to be supportive of the buffer stock saving model as a plausible alternative to the classic Permanent Income Hypothesis in explaining consumption dynamics. $^{2}$

Moreover, the recent emergence of an "equity culture" among a sizeable proportion of households has stimulated research in generalizing the single asset saving model to allow for portfolio choice between risky and riskless financial assets. ${ }^{3}$ An emerging literature on portfolio selection has stressed the importance of borrowing and short sales constraints. Cocco, Gomes and Maenhout (1999) and Gakidis (1998) solve numerically a model with short sales and borrowing constraints over the life cycle and in the presence of undiversifiable labor income risk, while Campbell, Cocco, Gomes, Maenhout and Viceira (1998) solve an infinite horizon model of optimal portfolio allocation when stock market returns exhibit mean reversion in the absence of individual labor income risk. Haliassos and Hassapis (1998) study the role of income- and collateral-based borrowing constraints and of their degree of tightness, and show that they tend to bias empirical estimates of precautionary effects downwards. Constantinides, Donaldson and Mehra (1998) argue that liquidity constraints faced by younger cohorts who expect higher earnings in the future can be one important component of a model that explains the equity premium, while Storeslettern, Telmer and Yaron (1998) show how a general equilibrium life cycle model with short sales and borrow-

\footnotetext{
${ }^{1}$ See, for example, Attanasio, Banks, Meghir and Weber (1999), Carroll and Samwick (1997, 1998); Hubbard, Skinner, and Zeldes (1995); Laibson, Repetto and Tobacman (1998); Ludvigson (1999).

${ }^{2}$ See Attanasio (1998) for an excellent recent survey of the literature on consumption.

${ }^{3}$ Recent empirical research on household portfolio choice and on its interaction with precautionary motives includes Guiso, Jappelli and Terlizzese (1996) and Attanasio, Banks and Tanner (1998).
} 
ing constraints and persistent idiosyncratic shocks can explain part of the observed equity premium puzzle.

Heaton and Lucas (henceforth HL, 1997,1999) study a model where infinitely lived households are faced with an asset menu of stocks and bonds and with uninsurable labor income shocks. In the absence of correlation between stock returns and earnings shocks, HL (1997) find that such a model yields complete portfolio specialization in stocks, and that this result is robust to habit persistence, transactions costs, risk aversion, and to an equity premium as low as two percent. HL (1999) find that positive correlation between stock returns and shocks to labor income (or income from business ownership) can mitigate the portfolio specialization result.

Existing empirical evidence on the correlation structure between earnings and stock returns across different population groups is scant. In one of the first studies attempting to quantify this correlation, Davis and Willen (1999) obtain estimates ranging between .1 and .3 over most of the working life for college educated males and around -.25 at all ages for male high school dropouts. ${ }^{4}$ Heaton and Lucas (1999) find that enterpreneurial risk is positively correlated with stock returns and reaches levels around .2. While positive correlation between earnings and stock returns is expected to discourage stockholding, negative correlation implies increased willingness to invest in the stock market as a hedge against earnings risk. Based on the empirical estimates of such correlations, low education households should be more heavily invested in the stock market while college graduates should tend to abstain from stock holding. Portfolio data are at variance with this implication, suggesting a strong positive correlation between education level and stock holding (see Mankiw and Zeldes, 1991, and Haliassos and Bertaut, 1995). ${ }^{5}$

This paper explores further the properties of the infinite horizon model and the sources of the complete portfolio specialization in stocks and offers an alternative explanation for observed stock holding patterns based on fixed stock market entry costs. We consider a

\footnotetext{
${ }^{4}$ They use the Annual Demographic Files of the March Current Population Survey (CPS) to construct panel data on mean annual earnings between 1963 and 1994.

${ }^{5}$ Mankiw and Zeldes use data from the Panel Study of Income Dynamics, while Haliassos and Bertaut employ the Survey of Consumer Finances.
} 
labor income process that allows us to decompose the consumption and portfolio effects of permanent and transitory shocks to labor income and show their interaction and relative importance in producing precautionary effects and the portfolio specialization result. We then derive an upper bound to the entry cost that would be required to keep households out of the stock market. This cost is surprisingly small, suggesting that entry costs arising from informational considerations, sign-up fees, and investor inertia could generate the observed reluctance of households to undertake stockholding. The finding that small costs can deter stockholding is also consistent with the observation that the recent emergence of an "equity culture" among households came in response to the proliferation and aggressive advertizing of mutual funds as well as to systematic education of workers regarding retirement accounts. On a purely technical side, we introduce a different numerical solution method that generalizes to portfolio models the technique proposed by Deaton (1991), and we use the invariant wealth distribution to compute time- and population averages.

Why is the stock market entry cost so surprisingly small? The answer lies with the fundamental conflict between impatience and prudence that the model captures. Individuals are impatient and therefore prefer to consume earlier rather than later. On the other hand, consumers are prudent; in the face of earnings uncertainty, they therefore build a small buffer of assets to cushion labor income shocks. In equilibrium, and for a plausible range of parameter values, individuals are liquidity constrained (save neither in the stock nor in the bond market) around thirty percent of the time. Moreover, mean saving is very small. Both factors make the gain from entering the stock market very small; thirty percent of the time the equity premium is given up due to the liquidity constraint, while for the rest of the times the gain is small due to the limited amount of savings. As a result, a small entry cost can deter a rational individual from entering the stock market.

The paper is organized as follows. Section 2 describes the economic environment in the portfolio and saving models. Section 3 discusses the numerical solution method for the portfolio model that generalizes the Deaton (1991) method for solving the saving model. Section 4 discusses policy functions and time series moments of consumption, stock and bond holdings, and the portfolio share of risky assets. It examines effects of risk aversion, and of precautionary motives arising from transitory and permanent shocks to labor incomes. 
Section 5 analyzes the effects of correlation between stock market returns and both types of labor income shocks. Section 6 derives threshold entry costs sufficient to keep households out of the stock market under alternative parameter configurations, while Section 7 concludes.

\section{The Model}

We consider the problem of an infinitely-lived household that maximizes expected intertemporal utility faced with a menu of a risky and a riskless asset. The household solves

$$
M A X_{\left\{B_{t}, S_{t}\right\}_{t=0}^{\infty}} E_{0} \sum_{t=0}^{\infty} \beta^{t} U\left(C_{t}\right)
$$

subject to

$$
\begin{gathered}
C_{t}+B_{t}+S_{t} \leq X_{t} \\
X_{t+1}=S_{t} \widetilde{R}_{t+1}+B_{t} R_{f}+Y_{t+1} \\
C_{t} \geq 0 \\
B_{t} \geq 0 \\
S_{t} \geq 0
\end{gathered}
$$

All variables are in real terms. $B_{t}$ and $S_{t}$ are real amounts of the riskless asset (bonds) and of the risky asset (stocks), respectively, that are held between the beginning of period $t$ and the beginning of period $t+1$. $E_{t}$ denotes the mathematical expectation operator based on information available up to the beginning of period $t$, while $\beta$ is the discount factor that satisfies $0<\beta<1$. $U\left(C_{t}\right)$ is the felicity derived from consumption in period $t, X_{t}$ is cash on hand at the beginning of period $t, \widetilde{R}_{t+1}$ is the risky gross return on stocks held between the beginning of period $t$ and that of period $t+1, R_{f}$ is the gross riskless rate which is assumed time-invariant, and $Y_{t}$ is labor income received at the beginning of period $t$.

The budget constraint (2) will hold with equality, given the assumption of non-satiation. We assume that the period-by-period felicity function is of the constant relative risk aversion (CRRA) form

$$
U\left(C_{t}\right)=\frac{C_{t}^{1-\rho}-1}{1-\rho}, \quad \rho \neq 1, \quad \rho>0
$$




$$
U\left(C_{t}\right)=\ln C_{t}, \quad \text { when } \rho=1 \text {. }
$$

Constraint (4) is never binding under CRRA utility, since $\lim _{C_{t} \rightarrow 0} U^{\prime}\left(C_{t}\right)=\infty$.

Constraints (5) and (6) are a direct generalization of the liquidity constraint imposed by Deaton in a single-asset model. The Deaton constraint precludes borrowing via short sales of the single asset, while (5) and(6) preclude short sales of either available asset, namely borrowing at the riskless or the risky rate. We refer to the benchmark model with no portfolio choice as the "saving model", since households can only choose $B_{t}$ and have no access to the stock market.

\subsection{Labor Income}

Labor income risk is nondiversifiable because of moral hazard and adverse selection considerations, and it cannot be ignored by households concerned about their consumption paths. We assume that labor income of household $i$ follows:

$$
Y_{i t}=P_{i t} U_{i t}
$$

where

$$
P_{i t}=G P_{i t-1} N_{i t}
$$

This process, first used in a nearly identical form by Carroll (1992), is decomposed into a "permanent" component, $P_{i t}$, and a transitory component, $U_{i t}$. We assume that $\ln U_{i t}$ and $\ln N_{i t}$ are each independent and identically (normally) distributed with means $\left\{-.5 * \sigma_{u}^{2}\right.$, $\left.-.5 * \sigma_{n}^{2}\right\}$, and variances $\sigma_{u}^{2}$ and $\sigma_{n}^{2}$, respectively. The lognormality of $U_{i t}$ and the assumption about the mean of its logarithm imply that

$$
E U_{i t}=\exp \left(-.5 * \sigma_{u}^{2}+.5 * \sigma_{u}^{2}\right)=1
$$

and similarly for $E N_{i t}$. Thus, precautionary wealth and portfolio effects can be computed despite the introduction of lognormally distributed multiplicative shocks. Computation of precautionary effects involves comparison of models in which household $i$ is guaranteed in period $t$ a certain level of income $\bar{Y}_{i t}$ versus models in which the same household faces income risk but still has expected income equal to $\bar{Y}_{i t}$. 
The $\log$ of $P_{i t}$, evolves as a random walk with a deterministic drift, $\ln G$, assumed to be common to all individuals. Denote the unconditional mean by $\mu_{g}$. Given these assumptions, the growth in individual labor income follows

$$
\Delta \ln Y_{i t}=\ln G+\ln N_{i t}+\ln U_{i t}-\ln U_{i t-1}
$$

where the unconditional mean growth for individual earnings is $\mu_{g}-.5 * \sigma_{n}^{2}$, and the unconditional variance equals $\left(\sigma_{n}^{2}+2 \sigma_{u}^{2}\right)$. Individual income growth in (12) has a single Wold representation that is equivalent to the $\mathrm{MA}(1)$ process for individual earnings growth estimated using household level data (MaCurdy [1982], Abowd and Card [1989], and Pischke $[1995]){ }^{6}$

\subsubsection{Calibration of Parameters}

We set the rate of time preference, $\delta$, equal to 0.1 , and the constant real interest rate, $r$, equal to 0.02. Carroll (1992) estimates the variances of the idiosyncratic shocks using data from the Panel Study of Income Dynamics, and our benchmark simulations use values close to those: around 0.1 percent per year for $\sigma_{u}$ and 0.08 percent per year for $\sigma_{n}$. We set the mean aggregate component of labor income growth denoted by $\mu_{g}$ equal to 0.03 and the coefficient of relative risk aversion equal to 8 . The mean equity premium equals 4.2 percent and its standard deviation is 18 percent. ${ }^{7}$ Numerical quadrature is used to take expectations, in the spirit of Tauchen (1986).

\section{Solution Method}

Analytical first order conditions for bonds and for stocks respectively can be written as follows:

$$
U^{\prime}\left(C_{t}\right)=\frac{1+r}{1+\delta} E_{t} U^{\prime}\left(C_{t+1}\right)+\lambda_{B}
$$

\footnotetext{
${ }^{6}$ Although these studies generally suggest that individual income changes follow an $\mathrm{MA}(2)$, the MA(1) is found to be a close approximation.

${ }^{7}$ Campbell, Lo and MacKinlay (1997, p.308) report the mean difference between the log real return on the $\mathrm{S} \& \mathrm{P} 500$ index and the real return on 6 -month commercial paper equal to 4.2 percent with a standard deviation equal to 17.74 percent. All data are annual, 1889 and 1994.
} 
and

$$
U^{\prime}\left(C_{t}\right)=\frac{1}{1+\delta} E_{t}\left[U^{\prime}\left(C_{t+1}\right) \widetilde{R}_{t+1}\right]+\lambda_{S}
$$

where $\lambda_{B}$ and $\lambda_{S}$ refer to the Lagrange multipliers for the no short sales constraints on bonds and on stocks. Recalling that the budget constraint in period $t$ is

$$
C_{t}=X_{t}-B_{t}-S_{t}
$$

where $X_{t}$ is cash on hand, a binding short sales constraint on bonds, implies that $C_{t}=X_{t}-S_{t}$ since bond holdings are at a corner of zero. Similarly, when the constraint preventing short sales of stock is binding, (15) implies that $C_{t}=X_{t}-B_{t}$. We generalize the Deaton (1991) solution to allow for portfolio choice by writing the two Euler equations in the following way:

$$
U^{\prime}\left(C_{t}\right)=M A X\left[U^{\prime}\left(X_{t}-S_{t}\right), \frac{1+r}{1+\delta} E_{t} U^{\prime}\left(C_{t+1}\right)\right]
$$

and

$$
U^{\prime}\left(C_{t}\right)=M A X\left[U^{\prime}\left(X_{t}-B_{t}\right), \frac{1}{1+\delta} E_{t} \widetilde{R}_{t+1} U^{\prime}\left(C_{t+1}\right)\right]
$$

Given the nonstationary process followed by labor income, we normalize asset holdings and cash on hand by the permanent component of earnings $P_{i t}$, denoting the normalized variables by lower case letters (Carroll, 1992). Defining $Z_{t+1}=\frac{P_{t+1}}{P_{t}}$ and taking advantage of the homogeneity of degree $(-\rho)$ of marginal utility implied by CRRA preferences, we have

$$
U^{\prime}\left(x_{t}-s_{t}-b_{t}\right)=M A X\left[U^{\prime}\left(x_{t}-s_{t}\right), \frac{1+r}{1+\delta} E_{t} U^{\prime}\left(c_{t+1}\right) Z_{t+1}^{-\rho}\right]
$$

and

$$
U^{\prime}\left(x_{t}-s_{t}-b_{t}\right)=M A X\left[U^{\prime}\left(x_{t}-b_{t}\right), \frac{1}{1+\delta} E_{t} \widetilde{R}_{t+1} U^{\prime}\left(c_{t+1}\right) Z_{t+1}^{-\rho}\right] .
$$

The normalized state variable $x$ evolves according to

$$
x_{t+1}=\left(s_{t} \widetilde{R}_{t+1}+b_{t} R_{f}\right) Z_{t+1}^{-1}+U_{i t+1}
$$


We use the identity $c_{t+1}=x_{t+1}-b_{t+1}-s_{t+1}$ where both $b_{t+1}$ and $s_{t+1}$ will be functions of $x_{t+1}$ to substitute out $c_{t+1}$ on the right hand sides of (18) and (19) (see appendix for the proposed algotrithm).

In order for the algorithm to work, we must make sure that the two functional equations of interest define a contraction mapping. The two conditions that must be satisfied for the individual Euler equations (18) and (19) to define a contraction mapping for $\{b(x), s(x)\}$ respectively are the conditions needed for Theorem 1 in Deaton and Laroque (1992) to hold. For (18) we must have

$$
\frac{1+r}{1+\delta} E_{t} Z_{t+1}^{-\rho}<1
$$

and for (19) the chosen parameters must satisfy

$$
\frac{1}{1+\delta} E_{t} \widetilde{R}_{t+1} Z_{t+1}^{-\rho}<1
$$

If these conditions hold simultaneously, there will exist a unique set of optimum policies satisfying the two Euler equations. We next simplify these conditions to gain an intuitive understanding of the economics of the problem. Given that $Z_{t+1}=G_{t+1} N_{t+1}$, with $\{G, N\}$ being log normally distributed and independent of each other, we have $E_{t}\left(G_{t+1} N_{t+1}\right)^{-\rho}=$ $\exp \left(-\rho \mu_{g}+\frac{\rho^{2} \sigma_{g}^{2}}{2}\right) * \exp \left(-\rho \mu_{n}+\frac{\rho^{2} \sigma_{n}^{2}}{2}\right)$. Assume for now that stock returns are uncorrelated with $Z$. Then

$$
\begin{aligned}
E_{t} \widetilde{R}_{t+1} Z_{t+1}^{-\rho} & =E_{t} \widetilde{R}_{t+1} E_{t} Z_{t+1}^{-\rho} \\
& =\left(1+\mu_{r}\right) * \exp \left(-\rho \mu_{g}+\frac{\rho^{2} \sigma_{g}^{2}}{2}\right) * \exp \left(-\rho \mu_{v}+\frac{\rho^{2} \sigma_{n}^{2}}{2}\right)
\end{aligned}
$$

Taking logs of the two conditions and using the approximation $\log (1+x) \approx x$ for small $x,(21)$ becomes

$$
\frac{r-\delta}{\rho}+\frac{\rho}{2}\left(\sigma_{g}^{2}+\sigma_{n}^{2}\right)<\mu_{g}+\mu_{n}
$$

which is the condition derived by Deaton (1991) with $\sigma_{g}^{2}=0$ and $\mu_{n}=0$. (22) becomes

$$
\frac{\mu_{r}-\delta}{\rho}+\frac{\rho}{2}\left(\sigma_{g}^{2}+\sigma_{n}^{2}\right)<\mu_{g}+\mu_{n}
$$


Note that the two conditions collapse into one when the stock market investment opportunity has the same return characteristics as the risk free rate.

With a positive equity premium $\left(\mu_{r}>r\right)$, satisfaction of (25) guarantees (24). Impatience must now be even higher than in the saving model to prevent the accumulation of infinite stocks, since the condition involving $\mu_{r}-\delta$ must be satisfied. Two other distinct cases can also guarantee the existence of a solution. First, a high expected earnings growth profile (as measured by $\mu_{g}$ ) guarantees that the individual will not want to accumulate an infinite amount of stocks or bonds but would rather borrow now, expecting earnings to increase in the future. Second, if the rate of time preference exceeds the expected stock return, more risk averse (higher $\rho$ ) individuals will not satisfy the convergence conditions.

\section{Labor Income Uncorrelated to Stock Returns}

\subsection{Portfolio Specialization and Effects of Risk Aversion}

In this Section, we solve the portfolio model for different degrees of (constant) relative risk aversion. Our findings confirm the puzzling result of complete portfolio specialization in stocks derived by Heaton and Lucas (1997) and show why it is robust to changes in risk aversion. Figures 1, 3, and 4 show respectively consumption, stock holdings, and bond holdings, each normalized by the permanent component of income, as functions of similarly normalized cash on hand. Figure 2 plots the share of financial wealth held in the risky asset for different levels of cash on hand. We consider risk aversion of 6,7 , and 8 .

Figure 1 shows that, at levels of normalized cash on hand below a cutoff $x^{*}$ (typically around $97 \%$ of the permanent component of labor income), the household does not save, as it is bound by both short sales constraints (Figs. 3 and 4). It would like to borrow at the riskless rate, expecting higher future realizations of cash on hand. Unable to do so, it is even willing to engage in short sales of stock so as to boost consumption, and the short-sales constraint on stocks binds.

The mechanism by which short-sales constraints on stocks and bonds justify zero stockholding in this range of normalized cash on hand can be seen as follows. In the absence of 
such constraints, an expected utility maximizer exhibits second-order risk aversion, in the sense that the premium it is willing to pay to avoid risk is proportional to the variance of the risk and goes to zero faster than the standard deviation of the risk (Segal and Spivak, 1990). Viewed from a different angle, households with no stocks will always choose to invest at least $\varepsilon$ in stocks, since stocks offer the equity premium and have (locally) zero covariance with the marginal utility of consumption. Now, as Haliassos and Bertaut (1995) have shown, imposition of a nonnegativity constraint on wealth, requiring

$$
A_{t}=S_{t}+B_{t} \geq 0
$$

cannot alter this result, because it treats bonds and stocks symmetrically. However, the presence of two separate short sales constraints for bonds and stocks with (potentially) different shadow values breaks this symmetry.

The policy function for normalized wealth is the difference between the 45-degree line and the policy function for consumption. Figure 1 shows that households with normalized cash on hand above $x^{*}$ start saving, but they first put all their savings in stocks. This confirms the portfolio specialization result of Heaton and Lucas (1997), for a different earnings process. The source of this result, and of its robustness to degrees of risk aversion, size of equity premia, and earnings processes, can also be seen with reference to the different shadow values of the two short-sales constraints. Combining (13) and (14) yields

$$
\frac{1}{1+\delta} E_{t}\left[U^{\prime}\left(C_{t+1}\right)\left(\widetilde{R}_{t+1}-R_{f}\right)\right]=\lambda_{B}-\lambda_{S}
$$

Under no stockholding and no correlation between earnings and stock returns, the covariance between the equity premium and the marginal utility of consumption is zero. Thus, equation (27) can be rewritten as

$$
\frac{1}{1+\delta} E_{t}\left[U^{\prime}\left(C_{t+1}\right)\right] E_{t}\left[\widetilde{R}_{t+1}-R_{f}\right]=\lambda_{B}-\lambda_{S}
$$

Given nonsatiation and an equity premium, the left hand side of (28) is positive, i.e. $\lambda_{B}>\lambda_{S}$. This difference in shadow values of relaxing constraints reflects the superior attributes of the riskless asset as a borrowing vehicle compared to the risky and costlier (in expected terms) alternative of short sales of stock. Since $\lambda_{B}>\lambda_{S}$ at zero stockholding, households in the 
neighborhood of $x^{*}$ would like to borrow risklessly not only to consume but also to invest in stocks that offer an equity premium and have zero covariance with consumption. Households are prevented from borrowing and devote all saving to stocks.

Changes in the degree of risk aversion cannot reverse this result, since they do not affect the sign of marginal utility. The same holds for habit persistence. As long as there is an equity premium, its size does not matter, either. This explains the robustness of the portfolio specialization result to the experiments in Heaton and Lucas (1997). As long as we consider earnings processes that are uncorrelated with stock returns, the nature of these processes does not influence this result, and $\lambda_{B}>\lambda_{S}$ continues to hold. This explains why we find portfolio specialization using a different earnings process.

Fig. 3 also shows that normalized stock holdings are increasing in risk aversion at levels of normalized cash on hand that justify saving. This surprising result is due to a conflict between risk aversion and "prudence" in the presence of binding short sales constraints. In an expected-utility framework, the degree of risk aversion is tied to the elasticity of intertemporal substitution and it is inversely related to it. Prudence is the tendency of an expected utility maximizer to accumulate additional wealth to buffer consumption from shocks to labor income (see Kimball, 1990), and it is positively related to risk aversion. Thus, higher risk aversion implies lower elasticity of substitution and higher prudence. Both make households want to increase their net wealth beyond $x^{*}$ (Fig. 1), but none of this increase comes from changes in realized borrowing, which is still at zero because of the binding short sales constraint (Fig. 4). Their desire to increase wealth dominates their motive to reduce exposure to stockholding risk, leading to increased stockholding for higher degrees of risk aversion.

Table 1 uses the invariant distribution of normalized cash on hand (see Appendix B) to show that mean and median bondholding are zero. Intuitively, and viewed in the context of an infinite-horizon household, this distribution indicates the proportion of time that the household receives normalized cash on hand realizations in each specified region. ${ }^{8}$ Consistent

\footnotetext{
${ }^{8}$ Viewed in the context of a continuum of households facing ex ante the same earnings process, it indicates the proportion of the population receiving, at a point in time, realizations of normalized cash on hand in each specified region.
} 
with policy functions, mean and median normalized stock holdings are not only positive, but also increasing in risk aversion. Such portfolio behavior by the more risk averse is justified, since it results in smaller standard deviation of normalized consumption, as well as in higher mean normalized consumption.

\subsection{Precautionary Effects}

\subsubsection{Policy Functions}

Let us now focus on the role of labor income risk in this type of portfolio behavior. Precautionary effects on asset accumulation are derived as differences from a model in which households are guaranteed the expected value of labor incomes. In the absence of short sales constraints, an expected utility maximizer will accumulate precautionary wealth to buffer consumption from shocks to labor income if the utility function exhibits prudence, i.e. has positive third derivative (Kimball, 1990). Kimball (1993) used an atemporal model to derive conditions under which uninsurable labor income risk discourages investment in a risky asset ("temperance"). ${ }^{9}$ Our CRRA utility function exhibits both properties. In the current setup, the answer to how wealth and portfolios are altered in response to uninsurable labor income risk involves a comparison between models in which short sales constraints are present.

Figures 5 to 8 depict the effects on policy functions from varying the standard deviation of permanent and of transitory shocks to labor income, for unchanged mean earnings. The benchmark standard deviations of transitory and permanent shocks are set to 0.1 and .08 respectively. Comparison to a model with no labor income risk shows the combined precautionary effects of both types of shocks. Comparison of the benchmark model to a setup without permanent shocks but with standard deviation of transitory shocks at the benchmark identifies the role of permanent shocks. ${ }^{10}$ Finally, comparison of this setup to the model with no earnings risk shows the role of transitory shocks.

When cash on hand is below a threshold $x^{*}$, total labor income risk from both sources

\footnotetext{
${ }^{9}$ See also Pratt and Zeckhauser (1987).

${ }^{10}$ Due to numerical problems with convergence, the case of "no" labor income risk involves standard deviations of transitory and of permanent shocks equal to 0.02 and 0.02 , respectively.
} 
has no effect on the policy functions for consumption and for asset holdings. Below this cash on hand threshold, both short sales constraints are binding regardless of whether labor income is risky. Thus, binding constraints eliminate precautionary effects on desired consumption, wealth, stockholding, and bondholding. In a second region of normalized cash on hand, earnings risk encourages wealth accumulation as expected, but it also encourages stockholding. Bond holdings are at the zero floor regardless of income risk. Prudence dictates a precautionary increase in wealth, and all of this increase is achieved through higher stockholding. As a result, the policy function for stockholding under labor income risk lies above that under income certainty (Fig. 7). ${ }^{11}$ Note that, had one looked only at the portfolio share of risky assets (Fig. 6), one would have missed these precautionary effects, since the predicted share is unity regardless of labor income risk.

In Figures 5-8, we also remove permanent shocks, maintaining transitory shocks. Figure 5 shows that removal of permanent labor income shocks encourages a substantial increase in normalized consumption (reduction in wealth) in the range above $x^{*}$, consistent with prudence. Figs. 7 and 8 demonstrate the major influence of permanent shocks on desired portfolio composition. As long as the short sales constraint on bonds is binding, removal of the permanent shock induces a decrease in stockholding. In this region, stocks act as precautionary buffers, and households take advantage of the equity premium to generate wealth in order to respond to the long term risk created by permanent shocks to labor income. In the absence of permanent shocks, the short sales constraint on bonds ceases to be binding at high normalized cash on hand, and bonds are substituted for stocks. Comparison of this intermediate setup to the model without earnings risk shows that the effects that transitory shocks have on policy functions are similar to those obtained for permanent shocks, but quantitatively much smaller.

\subsubsection{Time Series Moments}

Based on policy functions, we would expect that total labor income risk and permanent income shocks alone would increase mean and median stockholding substantially, while tran-

\footnotetext{
${ }^{11}$ Haliassos and Hassapis (1998) obtain similar reversals of temperance for a variety of income-based and collateral borrowing constraints in a model with finite horizons.
} 
sitory shocks would have a smaller effect. Table 2 demonstrates that time-series mean and median asset holdings are the joint product of policy functions and of the relative frequencies with which different levels of normalized cash on hand occur. Our expectations about permanent income shocks and total labor income risk are indeed confirmed. Contrary to results on policy functions, however, transitory shocks increase mean and median stockholding more than permanent shocks do.

The first column reports the case of no labor income risk. Starting from zero initial wealth, the household receives certain labor income that grows at $3 \%$ per period, and consumes it, since it cannot borrow. Thus, short sales constraints imply zero asset holding under no income risk. The second column introduces transitory shocks to labor income. Since asset holding can only be positive or zero, and given the portfolio specialization in stocks at likely levels of normalized cash on hand, mean and median normalized stockholding becomes positive but mean bondholding remains at zero. Thus, transitory shocks increase stockholding. Mean normalized consumption and consumption smoothing are enhanced through the use of stocks as a saving vehicle.

Column 3 introduces permanent shocks to labor income, but removes transitory shocks. Surprisingly, mean and median normalized stocks are below those under transitory shocks. Indeed, we find the biggest discrepancies in mean (and median) stockholding between the benchmark (col. 4) and column 3 in which transitory shocks are eliminated. Had we observed this in the data, we might be tempted to conclude that households subject to permanent shocks "dislike" stocks more than those subject to transitory shocks. However, this result is not due to policy functions but to the relative frequencies of cash on hand realizations. Not surprisingly, consumption smoothing is easiest under transitory shocks and too costly and difficult when only permanent shocks exist (see Deaton, 1991 for the same result in the saving model).

Taken together, the time series results represent an even bigger departure from our usual perception of temperance than those based on policy functions alone, since any type of labor income uncertainty boosts risky asset holdings in the presence of short sales constraints, thus contributing to the portfolio specialization result. 


\section{Correlation between stock market returns and labor income risk}

Our findings so far suggest that labor income shocks provide a major impetus for stockholding, thus contributing to the puzzling portfolio specialization result in the infinite-horizon model with uncorrelated stock returns and labor incomes. Positive correlation between labor incomes and stock market returns raises the covariance between the marginal utility of consumption and stock returns at any given level of stockholding. In the absence of short sales constraints, this should make stocks less attractive. We now examine whether the unrealistic portfolio specialization result can be eliminated by moderate correlation between stock returns and either transitory or permanent shocks to labor income under short sales constraints. The method used to induce positive correlation is described in Appendix A.

In unreported experiments, we found that positive correlation between stock returns and transitory earnings shocks is unlikely to be important in reversing the portfolio specialization result. Correlation equal to 0.2 yields small effects on policy functions. Correlation of unity induces households to move first into bonds, but portfolio specialization in stocks continues to occur for most of the relevant range of normalized cash on hand. At any rate, there is no empirical support for assuming that such extreme levels of correlation characterize an important subset of the population.

Figures 9 to 12 illustrate the effects of positive correlation between stock returns and permanent shocks to labor income equal to $0.1,0.3$, and 0.5 . The increased correlation between stock returns and permanent income shocks makes stocks significantly less attractive and induces households to start investing in bonds at lower levels of normalized cash on hand (Fig. 12). For correlation of 0.3 , the household still enters the stock market first, but the range of cash on hand for which only stocks are used is already severely limited (Fig. 11). At correlation of 0.5 , we find sizeable portfolio shifts away from stocks, a reversal in the order in which the household enters the stock and the bond market that is more in line with empirical observation, and a justification for zero stockholding in a likely range of normalized cash on

hand. In Table 4, a positive correlation of 0.5 drives mean and median stock holdings to 
zero, while mean and median bond holdings are positive. This improvement in portfolio predictions comes with minor effects on the policy function for consumption (wealth).

The empirical question then arises whether such levels of positive correlation between permanent earnings shocks and stock returns characterize a sufficiently large segment of the population to account for the zero stock holding puzzle. In one of the first studies attempting to quantify this correlation, Davis and Willen (1999) obtain estimates ranging between .1 and .3 over most of the working life for college educated males and around -.25 at all ages for male high school dropouts. ${ }^{12}$ Heaton and Lucas (1999) argue that enterpreneurial risk is positively correlated with stock returns and reaches levels around .2. These numbers appear smaller than needed to explain zero stockholding. Moreover, they are of the opposite sign for these categories; they come close to generating zero stockholding for college graduates or enterpreneurs who in fact tend to hold stocks, and they predict that low education households should actually be holding stocks as a hedging instrument when in fact they tend not to do so.

\section{Zero Stockholding and Entry Costs}

In this section we explore an alternative route to accounting for zero stockholding. Suppose that access to stockholding opportunities entails some cost. Such costs arise naturally, given the informational requirements for investing in the stock market and commissions charged by brokers and fund managers. They are augmented if one includes the opportunity cost of the household's time spent, as well as possible misperceptions about the level of costs and effort required to participate in the stock market that generate inertia (see Haliassos and Bertaut, 1995). We can then compute the normalized entry cost to the stock market that would make agents indifferent between entering the stock market or not participating and using the riskless asset market to generate the wealth buffer.

To compute this threshold entry cost, we solve for the associated value functions. Details of its computation are found in Appendix C. Not surprisingly, the value function of the

\footnotetext{
${ }^{12}$ They use the Annual Demographic Files of the March Current Population Survey (CPS) to construct panel data on mean annual earnings between 1963 and 1994.
} 
portfolio model exceeds that of the saving model at any level of normalized cash on hand, since households are no worse off when they have the option to invest in stocks (Figs. 13 and 14). Positive correlation between stock returns and permanent shocks to labor incomes lowers the value function for the portfolio model since it makes stocks less useful for buffering labor income risk (but still remains above the value function for the saving model).

Formally, if we denote the value function associated with participating in the stock market by $V_{s}$ and the value function when using the bond market by $V_{B}$, the normalized threshold entry cost as a function of normalized cash on hand is $k(x)$, such that

$$
V_{S}(x-k(x))=V_{B}(x)
$$

Given the monotonicity in cash on hand of the value function, we can use a numerical interpolation procedure to invert the value functions and derive the entry cost as

$$
k(x)=x-V_{S}^{-1}\left(V_{B}(x)\right)
$$

Since $k(x)$ varies with the realized cash on hand, we can now make use of the time-invariant distribution of normalized cash on hand ${ }^{13}$ to find the maximum level of $x$ that the household is likely to experience. We compute this from the invariant distributions depicted in Figs. 17-20 as the level $\widehat{x}$, such that $\operatorname{Pr}(x \leq \widehat{x})=1$. Our threshold entry cost is then computed as $k(\widehat{x}) \cdot{ }^{14}$

This threshold entry cost, or equivalently the minimum compensation that any household in the model would accept in order to stay out of the stock market, is an overestimate of the entry cost needed to generate observed population splits between stockholders and nostockholders in at least three respects. First, it is computed using a model which implies that, if the household gains access to the stock market, it can make use of stockholding opportunities over an infinite horizon. Second, we have assumed that the cost of accessing the stock market is a ticket fee that is paid only once. Third, we use the value $k(\widehat{x})$, which is sufficient to keep everybody out of the stock market regardless of cash on hand realization.

\footnotetext{
${ }^{13}$ See Appendix B for the computation of the time invariant distribution.

${ }^{14}$ We use the invariant distribution associated with the saving model to compute $\widehat{x}$ since we are assuming that the household is contemplating entry in the stock market for the first time.
} 
As seen from Figs. 15 and 16, $k(x)$ is monotonically increasing in $x$, implying that wealthier individuals require larger compensation to stay out of the stock market.

Despite these considerations, the computed threshold entry costs tend to be relatively small. For a household with risk aversion of 2 whose labor income is uncorrelated with stock returns, the threshold is $4.1 \%$ of the permanent component of labor income. On the other hand, when the coefficient of relative risk aversion rises to 8 , the threshold entry cost correspondingly rises to $15.9 \%$. The reason for the higher entry cost arises from the conflict between prudence and risk aversion. When risk aversion rises, prudence also rises to the point that prudence dominates risk aversion and dictates that more wealth be accumulated in the form of stocks. Since the importance of stocks is enhanced, the compensation for abstaining from the stock market has to rise, and therefore a higher entry cost must exist to rationalize stock market non-participation.

When the permanent shocks to labor income have correlation with stock returns equal to 0.3 and $\rho=2$, the threshold drops somewhat to $3.3 \%$ (from $4.1 \%$ when the correlation is zero) because of the reduced attractiveness of stocks. Interestingly, figure 16 shows that the presence of positive correlation can reverse the effect of higher risk aversion on the entry cost that induces stock market non-participation. When the household has risk aversion equal to 8 , for instance, the threshold drops further to $2.5 \%$ (recall that in the absence of positive correlation between stock returns and earnings the threshold rises with $\rho$; compare figures 15 and 16). This occurs because with positive correlation between earnings and stock returns, any given amount of stock holding contributes more to the riskiness of consumption, enhancing the importance of risk aversion relative to prudence. Viewed as overestimates of the necessary entry costs, these figures suggest that relatively small costs associated with information acquisition, commissions, time spent, and perhaps even inertia, could keep households out of the stock market.

One may wonder why entry costs are so low, given that the household gains access to stocks over an infinite horizon. Two factors are at work. First, access to stocks does not necessarily imply stockholding in every period. The invariant distributions for portfolio models in Figs. 18 to 20, combined with the policy functions for stockholding in Figs. 3 and 11 show that households are likely to spend a substantial fraction of their time at levels 
of normalized cash on hand that do not justify any stockholding. Specifically, when $\rho=2$ and stock returns are uncorrelated with labor income, the household does not save anything $\left(c<x^{*}\right)$ around $38 \%$ of the time. When the coefficient of relative risk aversion rises to 8 , on the other hand, the liquidity constraint is binding only $9.7 \%$ of the time, enhancing the value of entering the stock market and justifying the higher cost needed to generate stock market non-participation (cost rises from $4.1 \%$ to $15.9 \%$ of mean labor income). With positive correlation between stock returns and labor income and $\rho=2$, the household does not save anything approximately $47.3 \%$ of the time. Having zero saving for such substantial periods of time detracts from the appeal of having access to stocks and tends to lower the threshold entry costs. The empirical findings in Bertaut (1998), who used the panel sample of the Survey of Consumer Finances, are consistent with such behavior. Bertaut showed that zero stockholding in a given period is not confined to households that have never entered the stock market, but may also apply to households that previously held stocks.

A second reason for the low threshold costs arises from the total amount of saving after the stock market is entered. As tables 1-4 have illustrated, the total amount of saving is very small due to the impatience condition. Households build a small buffer of assets to smooth consumption fluctuations; mean normalized stock holdings when stock returns and labor income are uncorrelated equal .14 when $\rho=8$ and .032 when $\rho=2$. With correlation between stock returns and labor income equal to .3, mean stock holdings equal .11 when $\rho=8$ and .029 when $\rho=2$. Given the small asset accumulation implied by the model (a direct result of impatience and higher future expected earnings growth against which no borrowing is allowed), the benefit from entering the stock market is severely mitigated.

Although the infinite-horizon model is a good benchmark for computing the threshold entry costs that we described, it does not resolve all aspects of stockholding behavior. The model can account for zero stock holding and either zero or positive holdings of riskless assets by households that have never entered the stock market. On the other hand, it cannot account for the co-existence of positive portfolio holdings of stocks and riskless assets. Once the entry fee is paid, positive asset holding implies complete portfolio specialization in stocks for empirically plausible degrees of correlation between earnings and stock returns. Such coexistence is observed in the data for a subset of stockholders (King and Leape, 1984; Mankiw 
and Zeldes, 1991; Bertaut and Haliassos, 1997).

\section{Concluding Remarks}

This paper has extended Deaton's approach to solving single-asset models of saving, in order to incorporate portfolio choice subject to short sales constraints. In the absence of correlation between labor income shocks and stock returns, Heaton and Lucas (1997) find that the infinite-horizon household would abstain from both asset markets at low levels of normalized cash on hand, it would be fully invested in stocks for levels above a cutoff $x^{*}$, and it would combine bonds and stocks only at very high levels of normalized cash on hand. Heaton and Lucas (1999) argue that positive correlation between earnings and stock returns could eliminate the portfolio specilaization result.

Utilizing a different earnings process and computational method, we analyze further the properties of the infinite horizon model in the presence of liquidity constraints and undiversifiable labor income risk. We provide an explanation why risk aversion, habit persistence and the different earnings process cannot eliminate the portfolio specialization result. Moreover, we argue that existing empirical evidence seems to be at variance with the pattern of correlations required to explain stock holding by different segments of the population.

We therefore explore the potential of fixed entry costs to explain stock holding behavior. Specifically, we derive an upper bound to the entry cost required to keep households out of the stock market under different degrees of risk aversion and correlation between stock returns and labor income shocks. This threshold entry cost is small, suggesting that entry costs arising from informational considerations, sign-up fees, and investor inertia could generate the observed reluctance of households to undertake stockholding even when they hold liquid assets. They might also explain the delay in the spreading of an "equity culture" among households. A remaining puzzle, however, is the observed co-existence in portfolios of riskless assets and stocks in a subset of the population. Part of this puzzle is due to the assumed positive labor income floor which acts essentially as a riskless asset crowding out bond holdings. The alternative of assigning positive probability to a zero labor income state could also generate zero stock holding; whether it could also provide a plausible justification for the 
co-existence of bonds and stocks in the portfolio is an interesting topic for further research.

Another issue arises from the robustness of the theoretical findings to the assumed level of impatience. Unfortunately, this issue is difficult to address in the context of the infinite horizons model because of the parameter restrictions imposed by the impatience condition that must be satisfied for a contraction mapping. Alternatively, such analysis can be undertaken in a model with finite horizons that does not require such a condition; this is the subject of current research.

\section{A Appendix A: Numerical Dynamic Programming}

The pair of Euler equations are given by

$$
\begin{aligned}
U^{\prime}\left(x_{t}-s\left(x_{t}\right)-b\left(x_{t}\right)\right)= & M A X\left[U^{\prime}\left(x_{t}-s\left(x_{t}\right)\right), \beta E_{t} R_{f}\left(G_{t+1} N_{t+1}\right)^{-\rho} *\right. \\
& \left.U^{\prime}\left(x_{t}-s\left(x_{t+1}\right)-b\left(x_{t+1}\right)\right)\right]
\end{aligned}
$$

and

$$
\begin{aligned}
U^{\prime}\left(x_{t}-s\left(x_{t}\right)-b\left(x_{t}\right)\right)= & M A X\left[U^{\prime}\left(x_{t}-b\left(x_{t}\right)\right), \beta E_{t} \widetilde{R}_{t+1}\left(G_{t+1} N_{t+1}\right)^{-\rho} *\right. \\
& \left.U^{\prime}\left(x_{t+1}-s\left(x_{t+1}\right)-b\left(x_{t+1}\right)\right)\right]
\end{aligned}
$$

where $x_{t+1}=\left(s_{t} \widetilde{R}_{t+1}+b_{t} R_{f}\right) Z_{t+1}^{-1}+U_{i t+1}$. The single state variable (cash on hand, $\left.x_{t}\right)$ is discretized into 100 equidistant grid points between (.3 and 5). Given that the two conditions that guarantee that the above system defines a contraction mapping are satisfied, we can solve simultaneously for $\{s(x), b(x)\}$. Starting with any initial guess (say $s(x)=.1 * x$ and $b(x)=.1 * x)$, we use the right hand side of the first Euler equation to get an update for $b$ and continue doing so until $b$ converges to its time invariant solution $b_{1}^{*}$ (see Deaton (1991)). We then use the second Euler equation with $b_{1}^{*}$ taken as given, to find the solution for the time invariant optimal $s$, call it $s_{1}^{*}$. We know have two updated functions $\left\{s_{1}^{*}, b_{1}^{*}\right\}$; the process can be repeated until these functions converge to their time invariant solutions (this 
in practice depends on the parameters of the problem but is much faster than using a grid search method to pick the values of $\{b, s\}$ that would maximize the value function).

\section{A.0.3 Contemporaneous Correlation}

To find the probabilities associated with different state realizations in the presence of contemporaneous correlation, we discretize the joint probability distribution of a bivariate standard normal in the following way. The univariate standard normal distribution is divided into ten equiprobable intervals using eleven points; $\{ \pm 10, \pm 1.28155156, \pm 0.84162123, \pm 0.52440051, \pm 0.25334710$ A discrete approximation of the formula

$$
F\left(y_{1} \leq Y \leq y_{2}, z_{1} \leq Z \leq z_{2}\right)=F\left(y_{2}, z_{2}\right)-F\left(y_{2}, z_{1}\right)-F\left(y_{1}, z_{2}\right)+F\left(y_{1}, z_{1}\right)
$$

where $F$ is the bivariate standard normal of the two random variables $(Y, Z)$ is then derived using the $C D F B V N$ command in GAUSS.

\section{B Appendix B: Computing the Time- Invariant Dis- tribution}

Normalized cash on hand follows a renewal process and therefore has an associated invariant distribution. To find the time invariant distribution of cash on hand, we first compute the bond and stock policy functions; $b(x)$ and $s(x)$ respectively. Note that the normalized cash on hand evolution equation is

$$
\begin{aligned}
x_{t+1} & =\left[b\left(x_{t}\right) R_{f}+s\left(x_{t}\right) \widetilde{R}_{t+1}\right] \frac{P_{t}}{P_{t+1}}+U_{t+1} \\
& =w\left(x_{t} \mid \widetilde{R}_{t+1}, \frac{P_{t}}{P_{t+1}}\right)+U_{t+1}
\end{aligned}
$$

where $w(x)$ is defined by the last equality and is conditional on $\left\{\widetilde{R}_{t+1}, \frac{P_{t}}{P_{t+1}}\right\}$. Denote the transition matrix of moving from $x_{j}$ to $x_{k},{ }^{15}$ as $T_{k j}$. Let $\Delta$ denote the distance between the

\footnotetext{
${ }^{15}$ The normalized grid is discretized between $(x \min , x \max )$ where $x$ min denotes the minimum point on the equally spaced grid and $x$ max the maximum point.
} 
equally spaced discrete points of cash on hand on the grid. The risky asset return $\widetilde{R}$ and $\frac{P_{t}}{P_{t+1}}$ are discretized using 10 grid points respectively: $R=\left\{R_{l}\right\}_{l=1}^{l=10}$ and $\frac{P_{t}}{P_{t+1}}=\left\{G N_{m}\right\}_{m=1}^{m=10}$. $T_{k j}=\operatorname{Pr}\left(x_{t+1=k} \mid x_{t=j}\right)$ is found using

$$
\sum_{l=1}^{l=10} \sum_{m=1}^{m=10} \operatorname{Pr}\left(x_{t+1} \mid x_{t}, \widetilde{R}_{t+1}=R_{l}, \frac{P_{t}}{P_{t+1}}=N_{m}\right) * \operatorname{Pr}\left(\widetilde{R}_{t+1}=R_{l}\right) * \operatorname{Pr}\left(\frac{P_{t}}{P_{t+1}}=N_{m}\right)
$$

where both the independence of $\left(\widetilde{R}_{t+1}, \frac{P_{t}}{P_{t+1}}\right)$ from $x_{t}$ and the independence of $\frac{P_{t}}{P_{t+1}}$ from $\widetilde{R}_{t+1}$ were used. Numerically, this probability is calculated using

$$
T_{k j l m}=\operatorname{Pr}\left(x_{k}+\frac{\Delta}{2} \geqslant x_{t+1} \geqslant x_{k}-\frac{\Delta}{2} \mid x_{t}=x_{j}, \frac{P_{i t}}{P_{i t+1}}=N_{m}, R_{t+1}=R_{l}\right)
$$

Making use the approximation that for small values of $\sigma_{u}^{2}, U \sim N\left(\exp \left(\mu_{u}+.5 * \sigma_{u}^{2}\right),(\exp (2 *\right.$ $\left.\left.\left.\mu_{u}+\left(\sigma_{u}^{2}\right)\right) *\left(\exp \left(\sigma_{u}^{2}\right)-1\right)\right)\right)$, and denoting the mean of $U$ by $\bar{U}$ and its standard deviation by $\sigma$, the transition probability conditional on $N_{m}$ and $R_{l}$ then equals

$$
\begin{aligned}
T_{k j l m} & =\Phi\left(\frac{x_{k}+\frac{\Delta}{2}-w\left(x_{t} \mid N_{m}, R_{l}\right)-\bar{U}}{\sigma} \geqslant x_{t+1} \geqslant \frac{x_{k}-\frac{\Delta}{2}-w\left(x_{t} \mid N_{m}, R_{l}\right)-\bar{U}}{\sigma}\right. \\
\mid x_{t} & \left.=x_{j}, \frac{P_{i t}}{P_{i t+1}}=N_{m}, R_{t+1}=R_{l}\right)
\end{aligned}
$$

The unconditional probability from $x_{j}$ to $x_{k}$ is then given by

$$
T_{k j}=\sum_{l=1}^{l=10} \sum_{m=1}^{m=10} T_{k j l m} \operatorname{Pr}\left(N_{m}\right) \operatorname{Pr}\left(R_{l}\right)
$$

Given the matrix $T$, the probabilities of each of the states are updated by

$$
\pi_{k t+1}=\sum_{j} T_{k j} * \pi_{j t}
$$

so that the invariant distribution can be found by repeatedly multiplying the transition matrix by itself until all its columns stop changing. The invariant distribution $\pi$ is instead calculated (faster) as the normalized eigenvector of $T$ corresponding to the unit eigenvalue by solving the linear equations

$$
\left(\begin{array}{cc}
T-I & e \\
e^{\prime} & 0
\end{array}\right)\left(\begin{array}{l}
\pi \\
0
\end{array}\right)=\left(\begin{array}{l}
0 \\
1
\end{array}\right)
$$


where $e$ is an $M$-vector of ones.

Once the limiting distribution of cash on hand is derived, average cash on hand can be computed using

$$
\sum_{j} \pi_{j} * x_{j}
$$

Similar formulae can be used to compute the mean, median and standard deviations of the variables of interest, as reported in the tables.

\section{Appendix C: Value Function Computation}

An induction argument is sufficient to show that the value function inherits the properties of the utility function; in particular, the value function is homogeneous of degree $(1-\rho)$ when the utility function in of the CRRA form. As a result, the equation that determines the value function

$$
V\left(X_{t}, P_{t}\right)=M A X_{B_{t}, S_{t}} U\left(C_{t}\right)+\beta E_{t} V\left(X_{t+1}, P_{t+1}\right)
$$

can be rewritten as

$$
V\left(x_{t}\right)=M A X_{b\left(x_{t}\right), s\left(x_{t}\right)} U\left(c_{t}\right)+\beta E_{t}\left\{\frac{P_{t}}{P_{t+1}}\right\}^{1-\rho} V\left(x_{t+1}\right)
$$

Starting from any initial guess of the value function ( along with the optimal consumption, bond and stock policy functions on the right hand side of (39), we obtain an update of $V(x)$; this procedure can be repeated until the value function converges at all grid points.

\section{References}

[1] Abowd, John and Card, David, "On the Covariance Structure of Earnings and Hours Changes" Econometrica, 1989, 57, 411-45. 
[2] Attanasio, Orazio. 1998. "Consumption Demand." Forthcoming in the Handbook of Macroeconomics, edited by John B. Taylor and Michael Woodford.

[3] Attanasio, Orazio, James Banks and Sarah Tanner. 1998. "Asset Holding and Consumption Volatility." IFS Working Paper.

[4] Bertaut, Carol. 1998. "Stockholding Behavior of U.S. Households: Evidence from the 1983-89 Survey of Consumer Finances", Review of Economics and Statistics, 80, 263-75.

[5] Bertaut, Carol and Haliassos, Michael. 1997. "Precautionary Portfolio Behavior from a life-cycle perspective." Journal of Economic Dynamics and Control, 21, 1511-42.

[6] Campbell, John Y., Andrew W. Lo and A. Craig MacKinlay. 1997. The Econometrics of Financial Markets. Princeton, NJ, Princeton University Press.

[7] Campbell, John Y., Cocco F. Joao, Gomes J. Francisco, Pascal J. Maenhout and Viceira M. Luis. 1998. "Stock Market Mean Reversion and the Optimal Equity Allocation of a Long-Lived Investor" Harvard University Working Paper.

[8] Cocco F. Joao, Gomes J. Fransisco and Maenhout J. Pascal 1997. "Consumption and Portfolio Choice over the Life Cycle". Harvard University Working Paper.

[9] Carroll, Christopher D., 1992. "The Buffer-Stock Theory of Saving: Some Macroeconomic Evidence." Brookings Papers on Economic Activity no. 2: 61-156.

[10] Carroll, Christopher D., 'Buffer Stock Saving and the Life Cycle / Permanent Income Hypothesis' 1997, Quarterly Journal of Economics, CXII, 1, 3-55.

[11] Carroll, Christopher and Andrew Samwick. 1997. "The Nature of Precautionary Wealth." Journal of Monetary Economics, 40(1).

[12] Carroll, Christopher and Andrew Samwick. 1998. "How important is precautionary saving?" Review of Economics and Statistics 80(3): 410-19. 
[13] Constantinides, George, John Donaldson and Rajnish Mehra. 1998. "Junior Can't Borrow: A New Perspective on the Equity Premium Puzzle." Working paper, University of Chicago.

[14] Davis, Steven and Willen, Paul. 1999. "Using Financial Assets to Hedge Labor Income Risks: Estimating the Benefits." mimeo.

[15] Deaton, Angus. 1987. "Life-Cycle models of consumption: Is the evidence consistent with the theory?" in Truman F Bewley (Ed..) Advances in Econometrics, Fifth World Congress, Vol. 2, Cambridge and New York. Cambridge University Press, 121-48.

[16] Deaton Angus, 1991: 'Saving and Liquidity Constraints', Econometrica, Vol. 59, No.5, (September, 1991), 1221-1248.

[17] - and Laroque G., 1992, 'On the Behavior of Commodity Prices' Review of Economic Studies, 59, 1-23.

[18] Gakidis, Haralabos. 1998. "Stocks for the Old? Earnings Uncertainty and Life-Cycle Portfolio Choice." MIT, Ph.D. Thesis.

[19] Gollier C. and J.W. Pratt. 1996. "Risk Vulnerability and the Tempering Effect of Background Risk." Econometrica 64: 1109-1124.

[20] Gourinchas P. and Parker J. "Consumption over the Life Cycle" 1999, MIT mimeo.

[21] Guiso, Luigi, Tullio Jappelli and Daniele Terlizzese. 1996. "Income Risk, Borrowing Constraints and Portfolio Choice." American Economic Review vol. 86, pp. 158-172.

[22] Haliassos, Michael and Carol C. Bertaut. 1995. "Why do so few hold stocks?" The Economic Journal, 105, 1110-1129.

[23] Haliassos, Michael and Christis Hassapis, 1998, "Borrowing Constraints, Portfolio Behavior, and Precautionary Motives: Theoretical Predictions and Empirical Complications", mimeo, University of Cyprus. 
[24] Heaton John, and Deborah Lucas. 1996. "Evaluating the Effects of Incomplete Markets on Risk Sharing and Asset Pricing." Journal of Political Economy 104: 443-487.

[25] Heaton John, and Deborah Lucas. 1997. "Market Frictions, Savings Behavior, and Portfolio Choice." Macroeconomic Dynamics 1: 76-101.

[26] Heaton John, and Deborah Lucas. 1999. "Portfolio Choice in the Presence of Background Risk." July 1999. mimeo.

[27] Hubbard Glenn, Jonathan Skinner, and Stephen Zeldes. 1994. "The importance of precautionary motives for explaining individual and aggregate saving." in Allan Meltzer and Charles I Plosser, eds., The Carnegie Rochester Conference Series on Public Policy, XL (Amsterdam, North Holland).

[28] Hull, John. 1993. Options, Futures and Other Derivative Securities Prentice Hall Inc.

[29] Kimball, Miles S. 1990. "Precautionary saving in the small and in the large." Econometrica 58: 53-73.

[30] Kimball, Miles S. 1993. "Standard Risk Aversion." Econometrica 61: 589-612.

[31] King, Mervyn and Leape, Jonathan. 1984. "Wealth and Portfolio Composition: Theory and Evidence." NBER Working Paper 1468.

[32] Kocherlakota, Narayana. 1996. "The Equity Premium: It's Still a Puzzle." Journal of Economic Literature, Vol. XXXIV (March 1996), pp.42-71.

[33] Laibson, David, Andrea Repetto, and Jeremy Tobacman. 1998. "Self Controll and Saving for Retirement." Brookings Papers on Economic Activity 1: 91-196.

[34] Ludvigson Sydney. Forthcoming. "Consumption and Credit: A Model of Time Varying Liquidity Constraints." Review of Economics and Statistics.

[35] Ludvigson Sydney and Michaelides Alexander, "Can Buffer Stock Saving Explain the "Consumption Excesses"?" (1999) Federal Reserve Bank of New York Working Paper. 
[36] MaCurdy, T. E. 1981. "The use of time series processes to model the error structure of earnings in longitudinal data analysis." Journal of Econometrics. 18: 83-114.

[37] Mankiw, N. Gregory and Zeldes Stephen. 1991. "The Consumption of Stockholders and Non-Stockholders." Journal of Financial Economics, 29, 97-112.

[38] Pischke Jörn-Steffen, 1995, 'Indiividual Income, Incomplete Information and Aggregate Consumption' Econometrica, Vol.63, No.4, 805-840.

[39] Pratt, John and Richard Zeckhauser, 1987. "Proper Risk Aversion." Econometrica, vol. 55, pp. $143-154$.

[40] Segal, Uri and Spivak, Avia. 1990. "First Order versus Second Order Risk Aversion." Journal of Economic Theory, 51, 111-25.

[41] Storesletten, Kjetil, Telmer Chris and Yaron Amir. "Persistent Idiosyncratic Shocks and Incomplete Markets.” Working paper, Carnegie Mellon University, 1998.

[42] Tauchen, George. 1986. "Finite State Markov chain approximations to univariate and vector autoregressions." Economic Letters 20: 177-81. 
Table 1: Effects on consumption, bond and stock holdings from varying coefficient of relative risk aversion

$\begin{array}{llll} & \rho=6 & \rho=7 & \rho=8 \\ \text { Mean Normalized Bond Holdings } & 0.00 & 0.00 & 0.00 \\ \text { Mean Normalized Stock Holdings } & 0.09 & 0.11 & 0.14 \\ \text { Mean Normalized Consumption } & 1.004 & 1.005 & 1.006 \\ \text { Median Normalized Bond Holdings } & 0.00 & 0.00 & 0.00 \\ \text { Median Normalized Stock Holdings } & 0.07 & 0.09 & 0.11 \\ \text { Median Share of Wealth in Stocks } & 1.00 & 1.00 & 1.00 \\ \text { Median Normalized Consumption } & 1.009 & 1.009 & 1.009 \\ \sigma \text { (Normalized Bond Holdings) } & 0.00 & 0.00 & 0.00 \\ \sigma \text { (Normalized Stock Holdings) } & 0.08 & 0.10 & 0.12 \\ \sigma \text { (Normalized Consumption) } & 0.06 & 0.05 & 0.05 \\ \sigma \text { (Normalized Earnings) } & 0.10 & 0.10 & 0.10\end{array}$

Notes to Table 1: Normalized variables are with respect to the permanent component of labor income $\left(P_{i t}\right.$ in the text). The reported numbers are generated using the time invariant distributions associated with each model, as described in the text. Other parameters are set to $\delta=.1$, mean equity premium is 4.2 percent, standard deviation of excess returns is 18 percent, $\sigma_{u}=.1, \sigma_{n}=.08$. 
Table 2: Effects on consumption, bond and stock holdings from transitory and permanent labor income uncertainty

$\begin{array}{lllll} & \sigma_{u}=.02 & \sigma_{u}=.10 & \sigma_{u}=.02 & \sigma_{u}=.10 \\ & \sigma_{n}=.02 & \sigma_{n}=.02 & \sigma_{n}=.08 & \sigma_{n}=.08 \\ \text { Mean Norm Bonds } & 0.00 & 0.00 & 0.00 & 0.00 \\ \text { Mean Norm Stocks } & 0.00 & 0.05 & 0.01 & 0.14 \\ \text { Mean Norm Consumption } & 1.000 & 1.003 & 1.000 & 1.006 \\ \text { Median Norm Bonds } & 0.00 & 0.00 & 0.00 & 0.00 \\ \text { Median Norm Stocks } & 0.00 & 0.03 & 0.003 & 0.11 \\ \text { Median Share of Wealth in Stocks } & 1.00 & 1.00 & 1.00 & 1.00 \\ \text { Median Norm Consumption } & 1.00 & 1.005 & 1.004 & 1.009 \\ \sigma \text { (Norm Bonds) } & 0.00 & 0.00 & 0.00 & 0.00 \\ \sigma \text { (Norm Stocks) } & 0.00 & 0.06 & 0.01 & 0.12 \\ \sigma \text { (Norm Cons) } & 0.02 & 0.06 & 0.02 & 0.05 \\ \sigma \text { (Norm Earnings) } & 0.02 & 0.10 & 0.02 & 0.10\end{array}$

Notes to Table 2: See Table 1. 
Table 3: Effects on consumption, bond and stock holdings from varying the correlation between transitory labor income uncertainty and stock market risk

$\begin{array}{llll} & \text { Benchmark } & \text { Corr }=.2 & \text { Corr } \\ \text { Mean Normalized Bond Holdings } & 0.00 & 0.00 & 0.03 \\ \text { Mean Normalized Stock Holdings } & 0.14 & 0.14618511 & 0.03 \\ \text { Mean Normalized Consumption } & 1.006 & 1.006 & .97 \\ \text { Median Normalized Bond Holdings } & 0.00 & 0.00 & 0.03 \\ \text { Median Normalized Stock Holdings } & 0.12 & 0.12 & 0.00 \\ \sigma \text { (Normalized Bond Holdings) } & 0.00 & 0.00 & 0.03 \\ \sigma \text { (Normalized Stock Holdings) } & 0.12 & 0.13 & 0.09 \\ \sigma \text { (Normalized Consumption) } & 0.05 & 0.05 & 0.06\end{array}$

Notes to Table 3: See Table 1. Corr is the contemporaneous correlation between transitory labor income shocks and stock market returns.

Table 4: Effects on consumption, bond and stock holdings from varying the correlation between permanent labor income uncertainty and stock market risk

$$
\text { Benchmark Corr }=.1 \quad \text { Corr }=.3 \quad \text { Corr }=.5
$$

$\begin{array}{lllll}\text { Mean Norm Bonds } & 0.00 & 0.00 & 0.01 & 0.11 \\ \text { Mean Norm Stocks } & 0.14 & 0.14 & 0.11 & 0.00 \\ \text { Mean Norm Consumption } & 1.009 & 1.005 & 1.004 & 1.000 \\ \text { Median Norm Bonds } & 0.00 & 0.00 & 0.00 & 0.09 \\ \text { Median Norm Stocks } & 0.11 & 0.11 & 0.09 & 0.00 \\ \text { Median Share of Wealth in Stocks } & 1.00 & 1.00 & 1.00 & .00 \\ \text { Median Norm Consumption } & 1.009 & 1.009 & 1.007 & 1.007 \\ \sigma \text { (Norm Bonds) } & 0.00 & 0.00 & 0.02 & 0.09 \\ \sigma \text { (Norm Stocks) } & 0.12 & 0.11 & 0.08 & 0.00 \\ \sigma \text { (Norm Con) } & 0.05 & 0.05 & 0.05 & 0.05\end{array}$

Notes to Table 4: See Table 1. Corr is the contemporaneous correlation between permanent labor income shocks and stock market returns. 

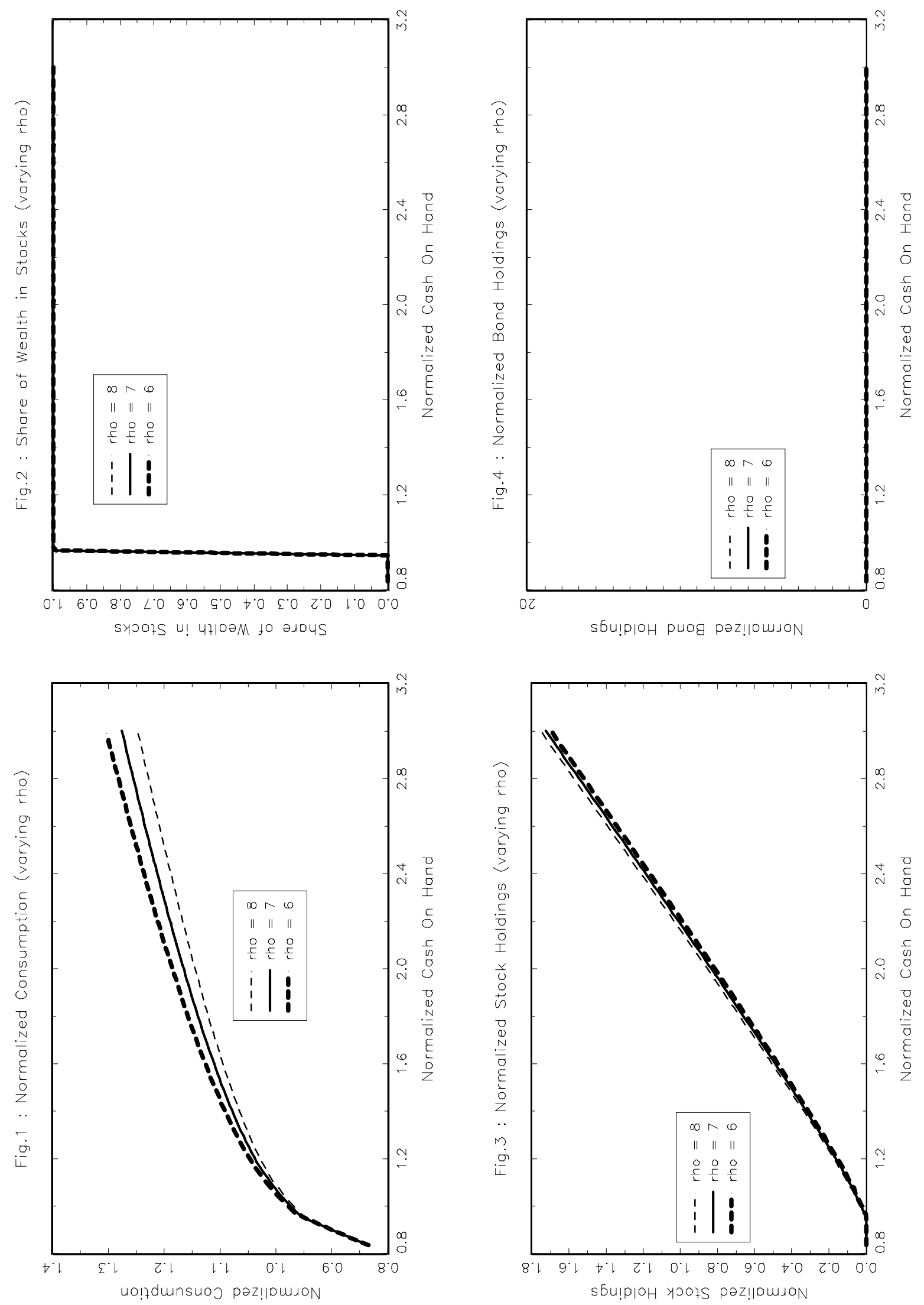

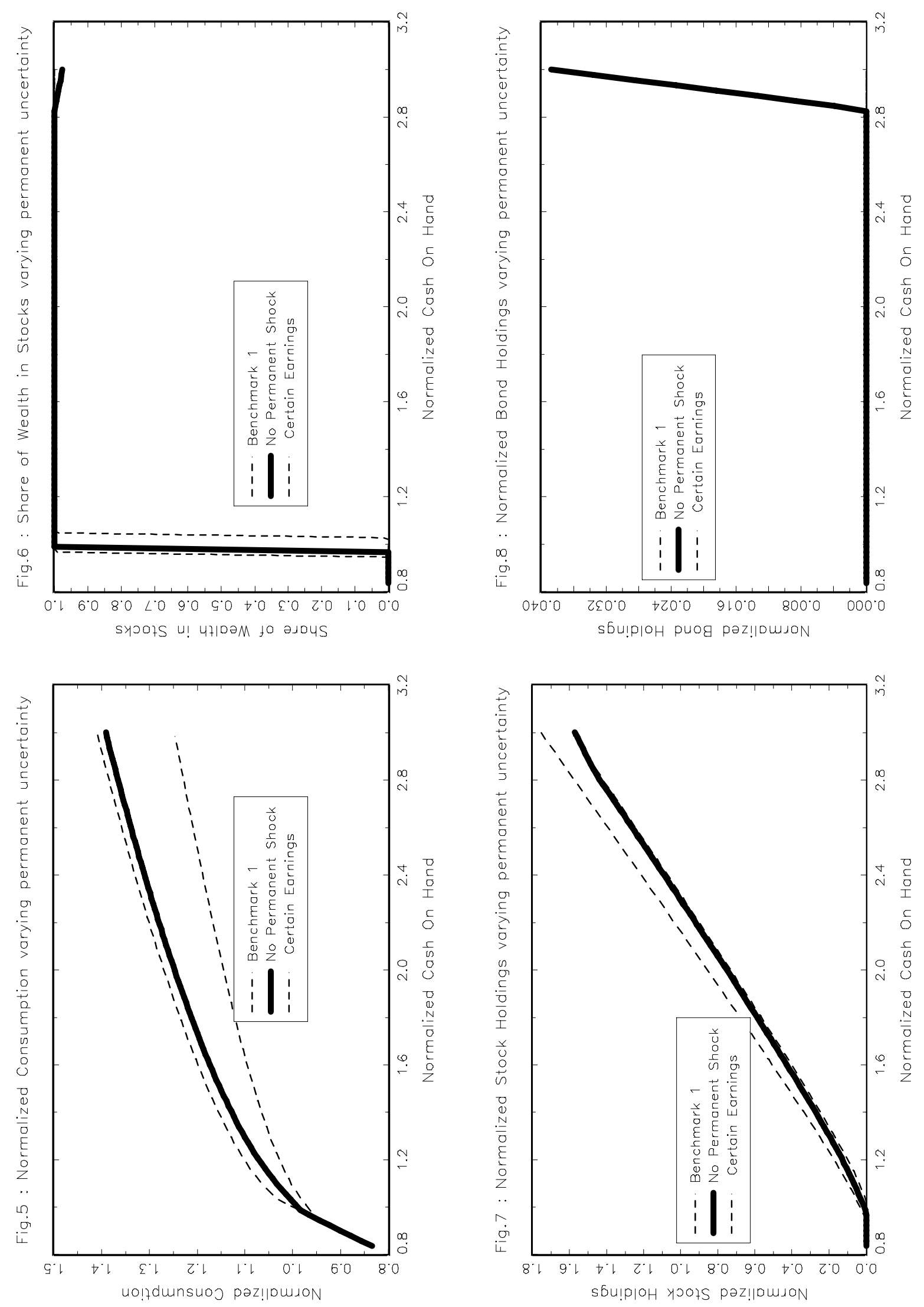

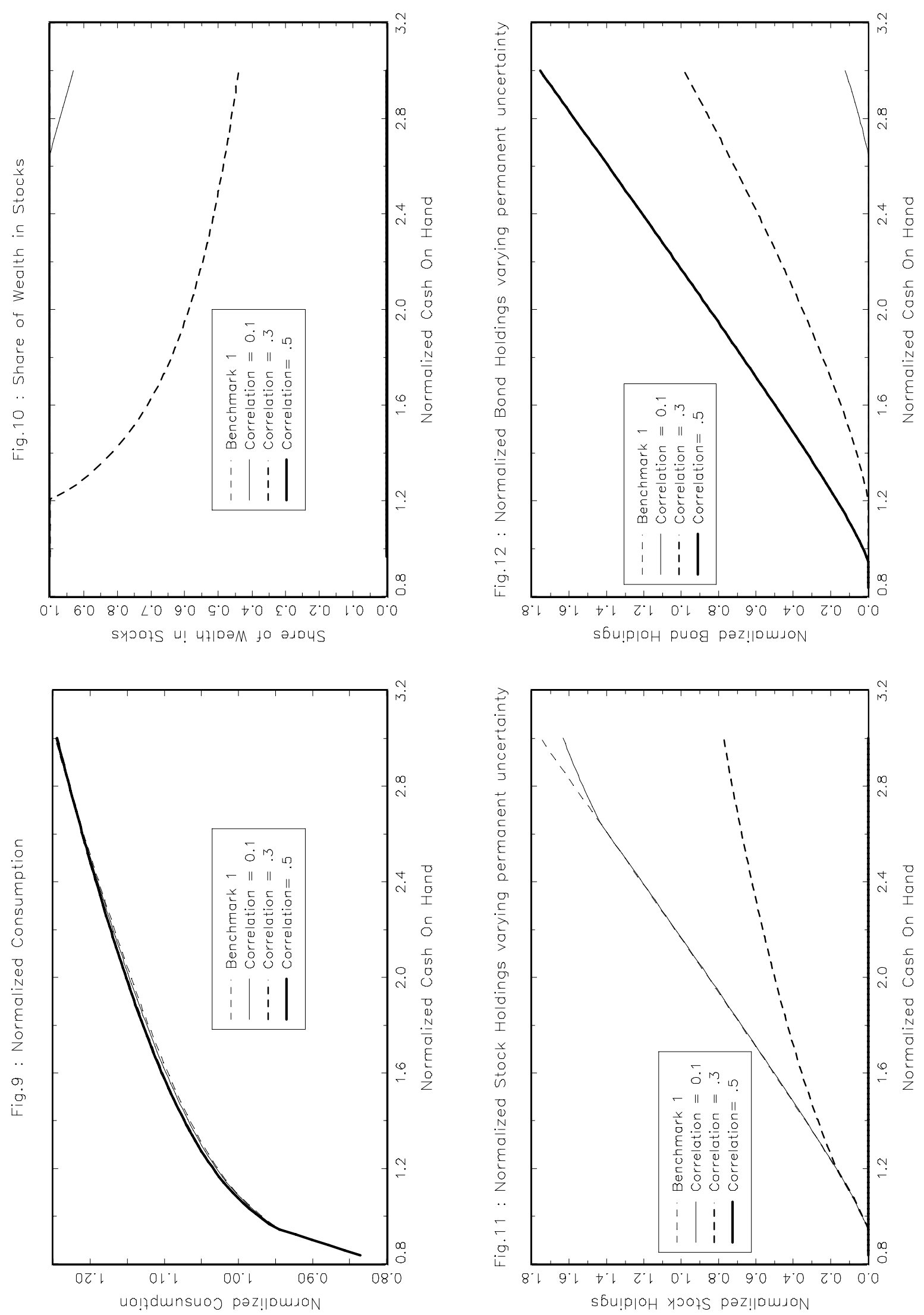

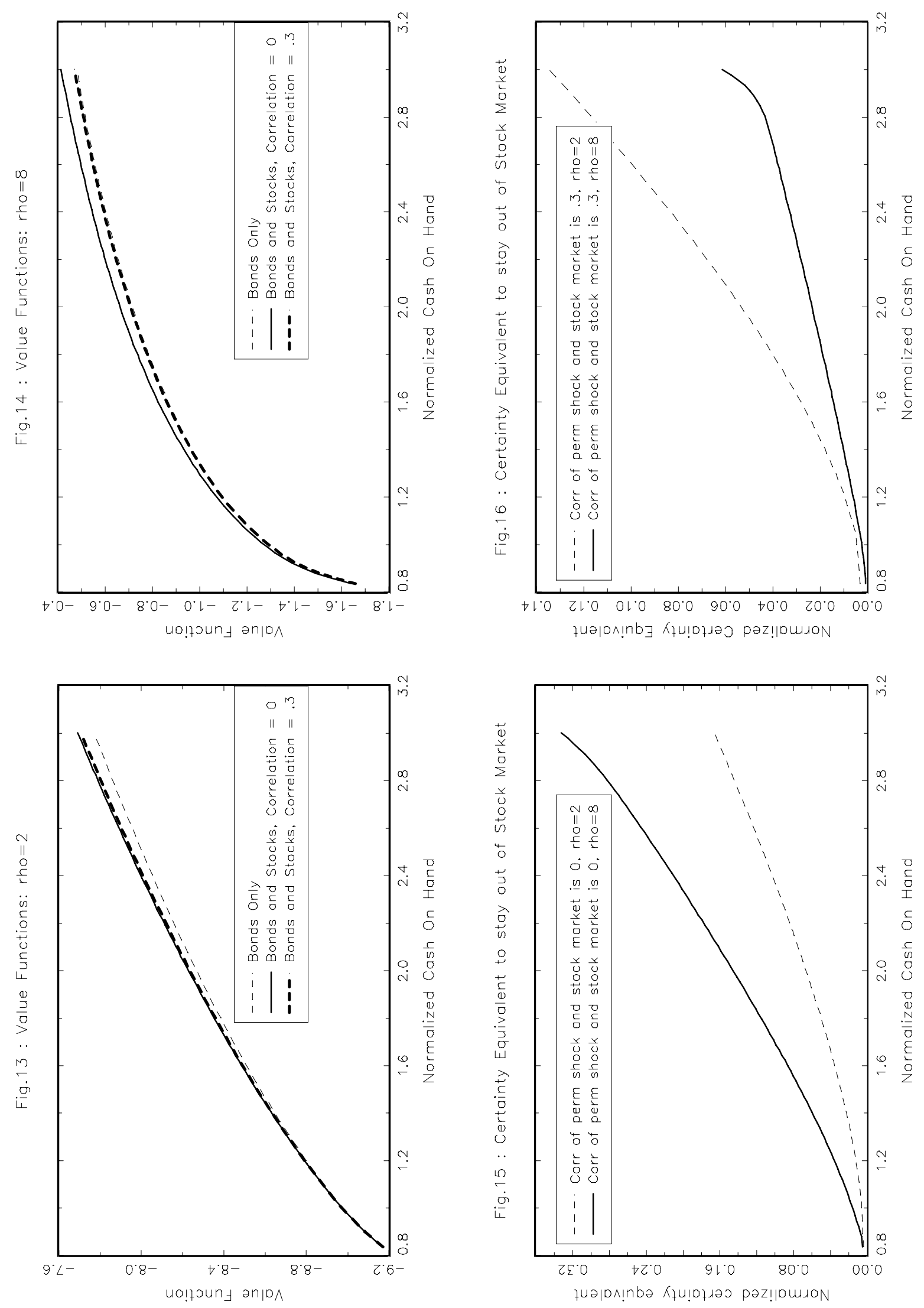

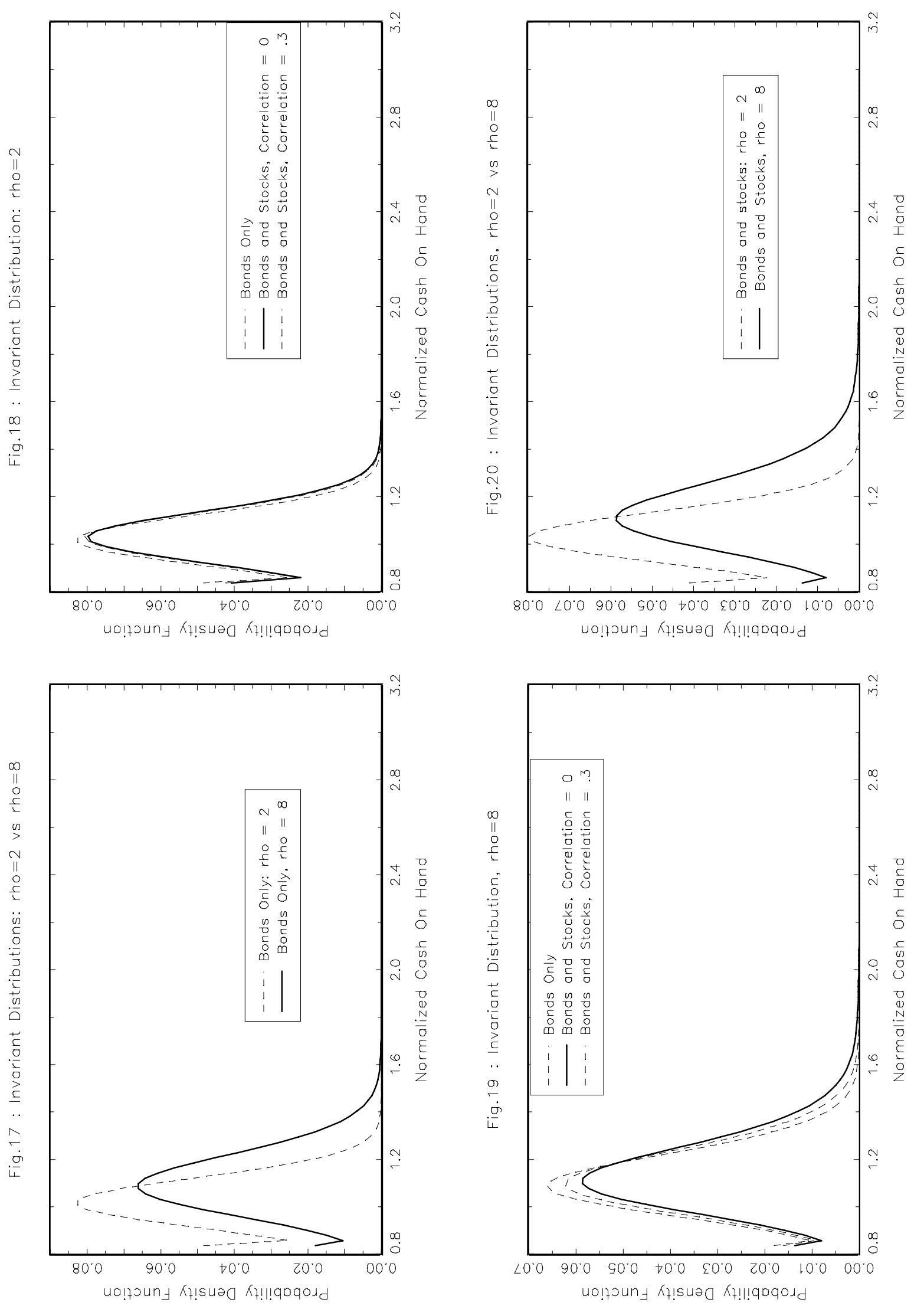